\title{
Carryover effects of pre- and postweaning planes of nutrition on reproductive tract development and estrous cycle characteristics in Holstein heifers
}

\author{
T. C. Bruinjé, ${ }^{1}$ J. P. Rosadiuk, ${ }^{1}$ F. Moslemipur, ${ }^{1,2}$ J. E. Carrelli, ${ }^{1}$ M. A. Steele,,${ }^{1,3}$ and D. J. Ambrose ${ }^{1,4 *}$ \\ ${ }_{1}^{1}$ Department of Agricultural, Food and Nutritional Science, University of Alberta, Edmonton, AB, Canada, T6G 2P5 \\ ${ }^{2}$ Department of Animal Science, Gonbad Kavoos University, PO Box 163, Golestan, Iran, 49717-99151 \\ ${ }^{3}$ Department of Animal Biosciences, University of Guelph, Guelph, ON, Canada, N1G 2W1 \\ ${ }^{4}$ Livestock Research Branch, Alberta Agriculture and Forestry, Edmonton, AB, Canada, T6H 5T6
}

\section{ABSTRACT}

The objectives of this study were to investigate the carryover effects of differing pre- and postweaning planes of nutrition on prepubertal reproductive tract development and postpubertal estrous cycle characteristics in Holstein heifers. Heifer calves $(\mathrm{n}=36)$ were randomly assigned to receive either a low or a high (5 or $10 \mathrm{~L}$ of whole milk/d, respectively) preweaning diet from 1 to 7 wk of age and either a low or a high $(70$ or $85 \%$ of concentrate dry total mixed ration, respectively) postweaning diet from 11 to 25 wk of age. Starting at wk 26 of age, heifers were subjected to weekly transrectal ultrasonography until wk 33 or until first ovulation to assess endometrial thickness and ovarian follicular count and size in the prepubertal phase. In a subset of heifers $(n=28)$, ovarian ultrasonography continued weekly until at least the second ovulation was confirmed; thereafter, ovarian dynamics (through ultrasonography) and blood progesterone (P4) were assessed every $2 \mathrm{~d}$ throughout 1 complete estrous cycle in the postpubertal phase. In the prepubertal phase, endometrial thickness $(12.0 \pm 0.4$ vs. $10.8 \pm 0.3 \mathrm{~mm})$ and largest follicle size $(11.8 \pm 0.3$ vs. $10.9 \pm 0.2 \mathrm{~mm})$ were greater in heifers fed the high postweaning diet than in those fed the low postweaning diet. Furthermore, the number of class $2(6-9 \mathrm{~mm})$ follicles was greater in heifers fed the high preweaning diet than in those fed the low preweaning diet $(1.6 \pm 0.1$ vs. $1.1 \pm 0.1)$, whereas the number of class $3(>9 \mathrm{~mm})$ follicles was greater in heifers fed the high postweaning diet than in those fed the low postweaning diet $(1.2 \pm 0.1$ vs. $1.0 \pm 0.1)$. In the postpubertal phase, overall corpus luteum and P4 dynamics did not differ among pre- or postweaning treatments; however, $\mathrm{P} 4$ at $4 \mathrm{~d}$ preceding luteolysis was lesser in heifers fed the high postweaning diet than in

Received January 3, 2019.

Accepted July 11, 2019.

*Corresponding author: divakar.ambrose@gov.ab.ca those fed the low postweaning $\operatorname{diet}(6.1 \pm 0.4$ vs. $7.7 \pm$ $0.4 \mathrm{ng} / \mathrm{mL}$ ). In addition, compared with heifers fed the low postweaning diet, those fed the high postweaning diet had a greater number of antral follicles (31.4 \pm 2.2 vs. $21.4 \pm 2.3)$ and tended to have more class 3 follicles $(3.6 \pm 0.3$ vs. $2.7 \pm 0.3)$. Results indicate positive carryover effects of increasing the preweaning plane of nutrition from 5 to $10 \mathrm{~L}$ of whole milk/d on prepubertal follicular growth in Holstein heifers. Furthermore, an increased postweaning plane of nutrition (85 vs. $70 \%$ of concentrate dry total mixed ration) advanced reproductive development through greater endometrial thickness and follicular growth in the prepubertal phase and increased the population of antral follicles in the postpubertal estrous cycle.

Key words: calf nutrition, endometrial thickness, heifer reproduction, ovarian activity, puberty

\section{INTRODUCTION}

Early-life nutrition has become a topic of increasing research interest because growth and development can affect future cow performance (Khan et al., 2011; Soberon and Van Amburgh, 2013). Increasing the plane of nutrition may increase operational cost (Davis Rincker et al., 2011); however, it can result in long-term economic advantages through reduced mortality (Godden et al., 2005), reduced age at first breeding (Radcliff et al., 2000), and improved productivity (Shamay et al., 2005) compared with a conventional lower plane of nutrition (Khan et al., 2011). Therefore, increasing the early-life plane of nutrition may result in increased lifetime performance, which is particularly relevant to the modern dairy industry.

In dairy cattle, development from birth to breeding age can be categorized into the preweaning, postweaning, and postpubertal phases. During the preweaning phase, increasing volumes of milk or milk replacer offered to calves to approximately $20 \%$ of birth BW per day compared with conventional feeding schemes 
of approximately $10 \%$ of birth BW per day has been associated with improved performance and welfare (as reviewed by Khan et al., 2011). For instance, positive effects of increasing the preweaning nutritional plane $(10$ vs. $5 \mathrm{~L} / \mathrm{d})$ were reported on ME intake, circulating IGF-1 (Haisan et al., 2018), body growth (Brown et al., 2005; Shamay et al., 2005; Rodríguez-Sánchez et al., 2015; Haisan et al., 2018), uterine development (Wilson et al., 2017), mammary development (Geiger et al., 2016), age at puberty (Shamay et al., 2005; Davis Rincker et al., 2011), and future milk production (Davis Rincker et al., 2011; Soberon and Van Amburgh, 2013). During the postweaning phase, increasing the plane of either protein or energy content, sometimes by increasing the concentrate:straw ratio in the diet, resulted in greater DMI and ADG (Groen et al., 2015), greater number and size of ovarian follicles (Armstrong et al., 2001; Chelikani et al., 2003), reduced age at puberty (Chelikani et al., 2003; Shamay et al., 2005; Nepomuceno et al., 2017) and at first breeding (Radcliff et al., 2000), improved pregnancy risk (Nepomuceno et al., 2017), and increased future milk yield (Shamay et al., 2005).

The improvement in reproductive parameters observed when an elevated plane of nutrition was offered is likely related to alterations in circulating metabolites and hormones linked to nutritional status. For instance, increased dietary protein and energy contents preweaning (2-8 wk of age) was associated with increased circulating IGF-1 and leptin, whereas increased protein and energy contents postweaning (8-14 wk of age) increased circulating IGF-1 in Holstein heifers (Brown et al., 2005). Similarly, Rosadiuk (2018) increased planes of nutrition during both the pre- and postweaning phases (1-7 and 11-25 wk of age, respectively) in Holstein heifers and reported increased circulating IGF-1 during both phases. Reduced circulating insulin and IGF-1 induced through nutrient restriction were associated with reduced dominant follicle size and LH pulse frequency in cycling beef heifers (Lents et al., 2013). Furthermore, increased circulating insulin and IGF-1 resulting from increasing the postpubertal plane of nutrition was associated with increased follicular recruitment (Gutiérrez et al., 1997) and growth of dominant follicles (Armstrong et al., 2001). Such studies demonstrate that differences in pre- and postweaning planes of nutrition alter metabolic profiles that are related to reproductive function.

Direct effects of differing nutritional planes on prepubertal follicular population (Chelikani et al., 2003), age at puberty (Chelikani et al., 2003; Rodríguez-Sánchez et al., 2015), and postpubertal circulating progesterone and follicular dynamics (Gutiérrez et al., 1997; Arm- strong et al., 2001; Chelikani et al., 2003) have been reported. However, potential carryover effects that preand postweaning planes of nutrition can have on subsequent reproductive tract development and reproductive physiology are yet to be studied. Therefore, the objectives of the present study were to investigate carryover effects of pre- and postweaning planes of nutrition on prepubertal reproductive tract development and on postpubertal estrous cycle characteristics in Holstein heifers. Specifically, we evaluated the effects of differing pre- and postweaning planes of nutrition before $26 \mathrm{wk}$ of age on (1) prepubertal endometrial thickness and ovarian follicular population beyond $26 \mathrm{wk}$ of age and (2) postpubertal ovarian dynamics and estrous activity during the estrous cycle.

\section{MATERIALS AND METHODS}

\section{Animals, Management, and Planes of Nutrition}

Animals were housed and cared for in accordance with the guidelines of the Canadian Council on Animal Care, and all experimental procedures were approved by the University of Alberta's Animal Care and Use Committee for Livestock (AUP no. 00001553).

Thirty-six Holstein heifer calves (average \pm SD birth $\mathrm{BW}=39.1 \pm 3.5 \mathrm{~kg}$ ) born between February and August 2017 at the Dairy Research and Technology Centre at the University of Alberta (Edmonton, AB, Canada) were enrolled in the study. At birth, each calf was preassigned to either a low or high $(5$ or $10 \mathrm{~L}$ of whole milk/d, respectively) preweaning dietary treatment and to either a low or high (70 or $85 \%$ of concentrate dry TMR, respectively) postweaning dietary treatment, forming 4 subgroups: low preweaning-low postweaning $(\mathbf{L L} ; \mathrm{n}=9)$, high preweaning-low postweaning (HL; $\mathrm{n}=9$ ), low preweaning-high postweaning $(\mathbf{L H} ; \mathrm{n}=$ 9), and high preweaning-high postweaning $(\mathbf{H H} ; \mathrm{n}=$ 9). Randomization of treatment allocation occurred by sequentially drawing 1 of the 4 subgroups (LL, HL, $\mathrm{LH}, \mathrm{HH}$ ) out of a hat for every 4 calves that were born at the research center. The distribution of calves into treatment groups was similar among different seasons of birth (winter, spring, or summer), dam parities (primiparous or multiparous), and categories of calving difficulty (assisted or unassisted).

Immediately after birth, calves were moved to individual stalls and offered $2 \mathrm{~L}$ of powder-based bovine dried colostrum (Headstart, The Saskatoon Colostrum Co. Ltd., Saskatoon, SK, Canada), with a minimum of $60 \mathrm{~g}$ of total $\mathrm{IgG}$, within $2 \mathrm{~h}$ of birth. Three additional 2-L colostrum feedings of whole pooled pasteurized (at $60^{\circ} \mathrm{C}$ for $60 \mathrm{~min}$ ) colostrum that measured a minimum 
refractometer value of $23 \%$ (Brix Refractometer, Misco, Solon, $\mathrm{OH}$ ), indicating at least $50 \mathrm{~g}$ of total $\mathrm{IgG}$, were offered 8, 16, and $24 \mathrm{~h}$ after the first colostrum feeding.

Following colostrum feeding, calves were assigned to receive either a low preweaning diet $(5 \mathrm{~L}$ of whole milk daily, delivered as two 2.5-L meals at 0615 and $1630 \mathrm{~h}$; $\mathrm{n}=18)$ or a high preweaning diet $(10 \mathrm{~L}$ of whole milk daily, delivered as four 2.5-L meals at 0615, 1130, 1630, and $2200 \mathrm{~h} ; \mathrm{n}=18)$. Milk was fed through a portable automated individual feeding system (CalfRail, Foerster-Technik, Engen, Germany) until $21 \pm 1 \mathrm{~d}$ of age with ad libitum access to water and, from $\mathrm{d} 7 \pm 1$ to $\mathrm{d}$ $21 \pm 1$, free access to a textured starter (Optivia Rumimax, Trouw Nutrition, Guelph, ON, Canada). At d 21 \pm 1 , calves were relocated to a group pen in the same facility with a stationary automated feeder (CF1000+, DeLaval Canada, Peterborough, ON, Canada) and fed the same preweaning diet with free access to starter and chopped straw (Skyline Harvest, Blumenort, MB, Canada). For both preweaning groups, the weaning transition started on d 50 with a 10\% daily reduction in total milk offered, and calves were completely weaned on d 60. After weaning, all calves had access to straw and starter for $5 \mathrm{~d}$, followed by a transition to a dry TMR with 85:15 starter:straw ratio, which was offered until d 80.

Calves were moved to an outdoor group pen facility at wk $10(\sim \mathrm{d} 75)$ of age and received either a low postweaning diet (70:30 starter:straw ratio dry TMR; $\mathrm{n}=18)$ or a high postweaning diet (85:15 starter:straw ratio dry TMR; same as the transition TMR; $\mathrm{n}=18$ ) starting at wk $11(\sim \mathrm{d} 80)$ until wk $25(\sim \mathrm{d} 180)$ of age. Such feeding schemes were based on a previous study that reported greater DMI and ADG in Holstein calves fed TMR containing 85:15 versus 70:30 concentrate: straw ratio from wk 17 to 23 of age (Groen et al., 2015). Feed was provided through individual automated feed bunks (Calan Broadbent Feeding System, American Calan Inc., Northwood, NH), and ad libitum feeding was simulated by increasing feed allocation when daily refusals were less than $10 \%$. Heifers had ad libitum access to water. Table 1 presents the composition of the milk, starter, and straw offered during the preweaning phase and of the dry TMR offered during the postweaning phase until wk 25. Starting at wk 26 of age until the end of the study, heifers were relocated to an adjacent pen of the same size and transitioned to a common diet of $2 \mathrm{~kg} / \mathrm{d}$ per heifer of a commercial ration comprising $15.4 \% \mathrm{CP}, 38.2 \%$ starch, and $1.7 \mathrm{Mcal} / \mathrm{kg}$ of ME (Advantage 4, Trouw Nutrition) and ad libitum access to an alfalfa-blend hay and water. A schematic representation of the study design timeline, including feeding and housing movements throughout the study, is presented in Figure 1.

\section{Prepubertal Phase}

Starting at 26 wk of age, all 36 heifers were enrolled in a weekly examination in a cattle chute, and BW and hip height were measured. At each examination, transrectal ultrasonography (US; Aloka 500V, Aloka Co. Ltd., Tokyo, Japan; equipped with a $7.5-\mathrm{MHz}$ linear array transrectal transducer) was conducted by 1 individual to assess endometrial thickness and ovarian structures. The endometrium was determined as the distance from the lower to the upper visualized inter-

Table 1. Composition of the preweaning (low vs. high) and postweaning (low vs. high) planes of nutrition offered as dietary treatments to 36 Holstein heifers

\begin{tabular}{|c|c|c|}
\hline Item & Low & High \\
\hline \multicolumn{3}{|l|}{ Preweaning phase $^{1}$} \\
\hline \multicolumn{3}{|l|}{ Pasteurized whole milk ${ }^{2}$} \\
\hline Amount fed (L/d) & 5.0 & 10.0 \\
\hline \multicolumn{3}{|l|}{ Chemical composition } \\
\hline CP (\% of DM) & 24.8 & 24.8 \\
\hline Crude fat (\% of DM) & 30.3 & 30.3 \\
\hline ME (Mcal/kg of DM) & 4.6 & 4.6 \\
\hline \multicolumn{3}{|l|}{ Starter } \\
\hline \multicolumn{3}{|l|}{ Chemical composition } \\
\hline $\mathrm{CP}(\%$ of $\mathrm{DM})$ & 22.4 & 22.4 \\
\hline Crude fiber ( $\%$ of DM) & 7.6 & 7.6 \\
\hline Starch & 22.3 & 22.3 \\
\hline ME (Mcal/kg of DM) & 2.6 & 2.6 \\
\hline \multicolumn{3}{|l|}{ Straw } \\
\hline \multicolumn{3}{|l|}{ Chemical composition } \\
\hline $\mathrm{CP}(\%$ of $\mathrm{DM})$ & 4.6 & 4.6 \\
\hline NDF (\% of DM) & 71.6 & 71.6 \\
\hline ME (Mcal/kg of DM) & 1.6 & 1.6 \\
\hline \multicolumn{3}{|l|}{ Postweaning phase $^{3}$} \\
\hline \multicolumn{3}{|l|}{ Ingredient (\% of DM) } \\
\hline Rumimax pellets ${ }^{4}$ & 46.5 & 56.5 \\
\hline Beet pulp pellets & 10.8 & 13.1 \\
\hline Rolled corn & 10.5 & 12.8 \\
\hline CFS mill mix ${ }^{4}$ & 2.1 & 2.6 \\
\hline Flavoring agent & 0.1 & 0.1 \\
\hline Concentrate & 70.0 & 85.0 \\
\hline Wheat straw & 30.0 & 15.0 \\
\hline \multicolumn{3}{|l|}{ Chemical composition } \\
\hline $\mathrm{CP}(\%$ of $\mathrm{DM})$ & 21.1 & 25.0 \\
\hline NDF ( $\%$ of DM) & 46.0 & 30.1 \\
\hline ME (Mcal/kg of DM) & 2.5 & 2.9 \\
\hline
\end{tabular}

${ }^{1}$ Preweaning dietary treatments occurred between 1 and 7 wk of age, followed by a weaning transition ( $10 \%$ daily reduction in milk offered) from 7 to 9 wk of age. From 9 to 11 wk of age, calves received a transition diet with $85 \%$ starter and $15 \%$ straw followed by weaning transition for $10 \mathrm{~d}$ and starter and straw, with composition similar to the high postweaning diet.

${ }^{2}$ Milk and starter intakes before 8 wk of age averaged (mean \pm SEM) $4.9 \pm 0.1 \mathrm{~L} / \mathrm{d}$ and $490.9 \pm 50.8 \mathrm{~g} / \mathrm{d}$, respectively, for heifers fed a low preweaning diet and $8.3 \pm 0.1 \mathrm{~L} / \mathrm{d}$ and $156.3 \pm 20.7 \mathrm{~g} / \mathrm{d}$, respectively, for heifers fed a high preweaning diet.

${ }^{3}$ Postweaning dietary treatments occurred between 11 and 25 wk of age and contained either a $70 \%$ (low postweaning diet) or $85 \%$ (high postweaning diet) concentrate dry TMR. Dry matter intake averaged (mean \pm SEM) $5.6 \pm 0.1 \mathrm{~kg} / \mathrm{d}$ for heifers fed a low postweaning diet and $6.6 \pm 0.1 \mathrm{~kg} / \mathrm{d}$ for heifers fed a high postweaning diet.

${ }^{4}$ Trouw Nutrition, Guelph, ON, Canada. 
faces between the endometrium and myometrium at the uterine body. During examination, the US image was frozen when the endometrium was determined visually to be at its largest diameter in a sagittal plane between the end of the cervix and the bifurcation of the uterine horns and was measured using the built-in calipers of the US device. Ovarian structures were examined by scanning each ovary from end to end in multiple planes to determine the position of the structures. The diameter of follicles smaller than $10 \mathrm{~mm}$ was estimated in a frozen image using the tick marks along the $y$ and $\mathrm{x}$-axes of the US device as a reference, whereas the diameter of follicles equal to or greater than 10 $\mathrm{mm}$ was determined as the average of 2 perpendicular diameters measured in a frozen US image using the built-in calipers. With this, the number of class 2 (6-9 $\mathrm{mm}$ diameter) and class 3 (>9 $\mathrm{mm}$ diameter) follicles and the size of the largest follicle determined at each weekly scan were recorded. The first ovulation was confirmed by the presence of a visible corpus luteum (CL) in either ovary and was considered indicative of puberty. As we aimed to evaluate endometrial thickness and follicular population during the prepubertal phase, measurements obtained the week before confirmation of puberty and later were not used for analysis. Four heifers had a CL at the first US examination at $26 \mathrm{wk}$, and 4 other heifers attained puberty between 26 and 28 wk of age; therefore, prepubertal data from these 8 heifers were not obtainable. Thus, the final data set for the prepubertal phase contained 28 heifers (9 LL, $5 \mathrm{LH}$, $9 \mathrm{HL}$, and $5 \mathrm{HH}$ ), of which prepubertal measurements from wk 26 to 33 of age were statistically analyzed.

\section{Postpubertal Phase}

Ovarian Ultrasonography. Regardless of whether heifers were included in the prepubertal phase evaluation, the first 7 heifers to achieve puberty within each subgroup (LL, LH, HL, and $\mathrm{HH}$ ) were continuously examined weekly using transrectal US for the evaluation of the postpubertal phase, including the 8 heifers (4 $\mathrm{LH}$ and $4 \mathrm{HH}$ ) excluded from the prepubertal

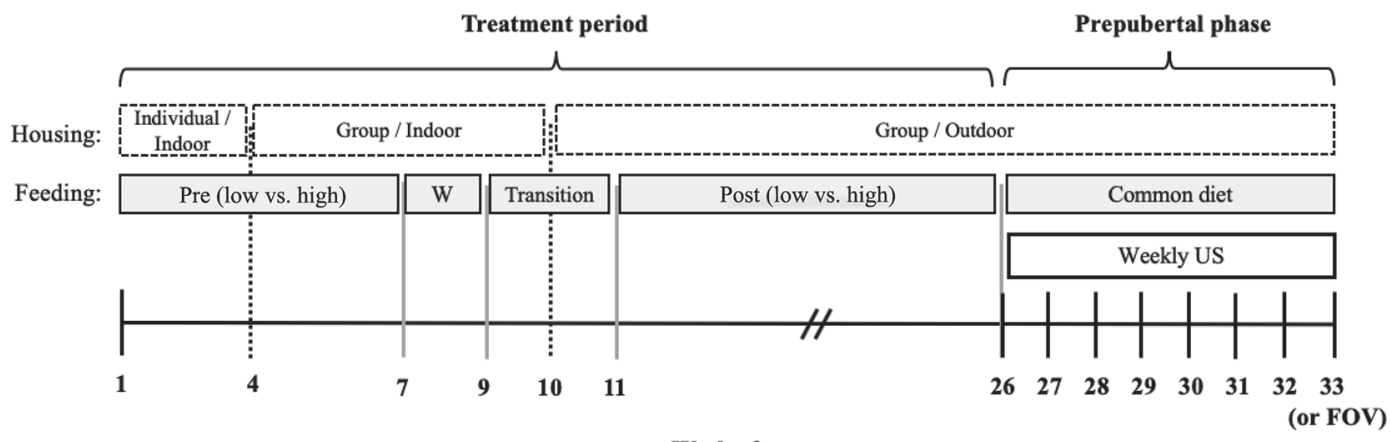

Week of age

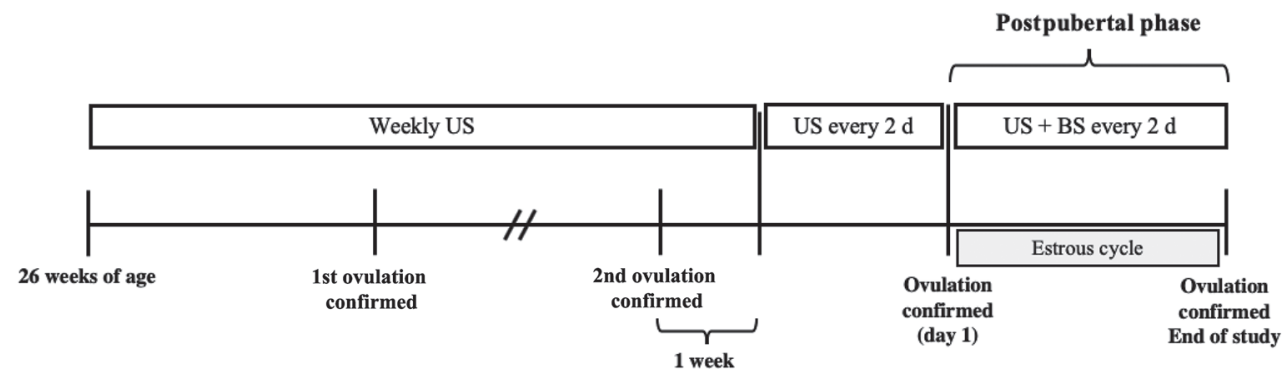

Figure 1. Schematic representation of the study design. Holstein heifer calves $(\mathrm{n}=36)$ were randomly assigned to receive either a low or high ( 5 or $10 \mathrm{~L}$ of whole milk/d, respectively) preweaning diet (Pre) from 1 to 7 wk of age, followed by a weaning transition (W; $10 \%$ daily reduction in milk offered) from 7 to 9 wk of age. From 9 to 11 wk of age, calves received a transition diet with $85 \%$ starter and $15 \%$ straw. From 11 to $25 \mathrm{wk}$ of age, calves were randomly assigned to either a low or high (70 or $85 \%$ concentrate dry TMR) postweaning diet (Post), ad libitum, with free access to water. Throughout the treatment period (i.e., until 25 wk of age), heifers were fed individually and thereafter received group feeding. Starting at 26 wk of age, heifers were offered a common diet with $2 \mathrm{~kg} / \mathrm{d}$ per heifer of a commercial ration and free access to alfalfa hay and water and were subjected to weekly transrectal ultrasonography (US) of the uterus and ovaries until puberty. Data respective to endometrial thickness and follicular population in the prepubertal phase were assessed until 33 wk of age or until 2 wk before first ovulation (FOV), whichever occurred first. A subset of heifers $(\mathrm{n}=28)$ continued to be examined by weekly US of the ovaries until confirmation of at least the second ovulation, characterizing the postpubertal phase. Thereafter, heifers were subjected to ovarian US and blood sampling (BS) every 2 d, and estrus was detected by an automated activity monitoring system until the final confirmed ovulation to monitor 1 complete estrous cycle. 
phase analysis. Heifers $(\mathrm{n}=28)$ were examined weekly until the second ovulation was confirmed. One week later, heifers were subjected to frequent ovarian US, performed every $2 \mathrm{~d}$ until 2 subsequent ovulations were confirmed, to monitor 1 complete postpubertal estrous cycle. After the frequent examinations began, the day on which a new ovulation was confirmed [day between the disappearance of a dominant follicle $(\geq 10 \mathrm{~mm})$ and the appearance of a CL in the same position] was defined as d 1 of the estrous cycle. The confirmation of the next subsequent ovulation was defined as the final ovulation and the end of the study, as indicated in Figure 1. Ovarian structures (CL and follicles) visualized in the US examinations throughout the estrous cycle were mapped and recorded. The CL volume was calculated as

$$
\text { volume }=\frac{4}{3} \times \pi \times\left(\frac{\frac{\text { length }}{2}+\frac{\text { width }}{2}}{2}\right)^{3} \text {, }
$$

and if a fluid-filled cavity was present within the CL, the cavity volume was calculated and subtracted from the total CL volume (Sartori et al., 2004). Two heifers had a double ovulation, for which the average volume of both CL was determined. As described elsewhere, ovarian follicles were examined by scanning each ovary from end to end in multiple planes. The antral follicle count, defined as the total number of all visible follicles $(\geq 2 \mathrm{~mm})$, was measured at $\mathrm{d} 1$ and counted from the US image simultaneously by 2 individuals, and the average count of both measurements was recorded. Furthermore, the number of class 2 and 3 follicles was measured at $\mathrm{d} 3$, and the size of the preovulatory follicle, defined as the dominant follicle $(\geq 10 \mathrm{~mm})$ at the end of the cycle that had disappeared within the immediate 2 US exams preceding the appearance of a newly formed CL in the same position, was recorded.

Blood Sampling and Progesterone Measurement. Throughout the estrous cycle, blood samples were collected every $2 \mathrm{~d}$ by jugular venipuncture into evacuated heparinized Vacutainer tubes (Becton Dickinson, Franklin Lakes, NJ). Samples were placed on ice upon collection and centrifuged at $1,500 \times g$ for 20 min at $4^{\circ} \mathrm{C}$, and plasma was harvested and stored at $-20^{\circ} \mathrm{C}$ until being assayed for progesterone $(\mathbf{P} 4)$. Plasma P4 concentrations were quantified at Endocrine Lab Services (University of Saskatchewan, Saskatoon, SK, Canada) using a commercial solid-phase RIA kit (ImmuChem; MP Biomedicals LLC, Orangeburg, NY) as in Gobikrushanth et al. (2017). The intra-assay coefficients of variation averaged $8.6 \%$ for low and $13.0 \%$ for high reference samples, the interassay coefficients were $11.7 \%$ for low (mean $=0.96 \mathrm{ng} / \mathrm{mL}$ ) and $15.7 \%$ for high (mean $=11.40 \mathrm{ng} / \mathrm{mL}$ ) reference samples, and the assay sensitivity was $0.11 \mathrm{ng} / \mathrm{mL}$.

For each heifer, the average of the 2 samples with the highest $\mathrm{P} 4$ concentrations of the cycle was defined as the $\mathrm{P} 4$ peak, and the slope to $\mathrm{P} 4$ peak was defined as the average daily increase in $\mathrm{P} 4$ between $\mathrm{d} 1$ and the day in which $\mathrm{P} 4$ increased to above or equal to the $\mathrm{P} 4$ peak concentration. The day of luteolysis was defined as the sampling day preceding the sample in which $\mathrm{P} 4$ declined to less than $50 \%$ of the $\mathrm{P} 4$ peak and was followed by a subsequent sample with P4 less than $25 \%$ of the P4 peak (adapted from Sartori et al., 2004). The average daily decrease in $\mathrm{P} 4$ between luteolysis and the subsequent sample with $\mathrm{P} 4$ less than $25 \%$ of the P4 peak was defined as the luteolysis slope. The luteal phase length was defined as the interval between confirmed ovulation (d 1) and luteolysis, and cycle length was defined as the interval between $\mathrm{d} 1$ and the confirmation of the next subsequent ovulation.

Estrous Activity. Heifers were fitted with an ear tag-based activity monitoring system (CowManager, Harmelen, the Netherlands), which consisted of a 3 -axis accelerometer sensor that, based on proprietary calculations, reported minutes per hour of increased activity. Peak estrous activity was defined as the average minutes per hour of increased activity during the day of the cycle that had the highest activity value recorded between the day of luteolysis and ovulation. Due to technical errors associated with data retrieval, activity data from only 21 heifers (10 low preweaning and 11 high preweaning; 13 low postweaning and 8 high postweaning) were consistently available for analysis. Activity data preceding the 2 confirmed ovulations (d 1 and the final ovulation) for each heifer were evaluated.

\section{Statistical Analysis}

Data were analyzed using SAS 9.4 (Studio 3.71 platform, SAS Institute Inc., Cary, NC). The MEANS procedure was used to obtain descriptive statistics. Continuous dependent variables were analyzed using the GLIMMIX procedure with models fitting a Gaussian distribution. For both pre- and postpubertal data sets, full models for dependent variables assessed over time (prepubertal phase: wk 26-33 of age; postpubertal phase: d 1-21 of the estrous cycle) included the fixed effects of preweaning diet, postweaning diet, the time component, and their interactions, with heifer as the repeated measures subject. In addition, models for the postpubertal phase included heifer age at $\mathrm{d} 1$ and dam gestation length as covariates because dam gestation length was not similar among treatment groups. 
Normality and homoscedasticity of standardized residuals were assessed graphically and, when applicable, logarithmic or square root transformation was used to improve normality of residuals. If transformation was used, the back-transformed least squares means (LSM) and respective $95 \%$ confidence interval were presented. When an interaction with the time component was present, the SLICE command was used to assess partitioned LSM by time point, with post hoc tests performed using Bonferroni adjustment. For non-normal count data, similar models were fitted using a Poisson distribution. For each model, the covariance structure resulting in the smallest Akaike information criterion was used and was either compound symmetry or firstorder autoregressive.

In the final models, independent variables to be retained were selected based on manual backward stepwise elimination that removed variables with $P>0.10$, except for preweaning diet and postweaning diet, which were deliberately kept. Dependent variables that were assessed at a single time point (e.g., antral follicle count and number of class 2 or 3 follicles in the postpubertal phase) were analyzed using similar models but excluding the time component and the repeated-measures statement. Relationships among variables were assessed by Pearson correlation coefficient tests using the CORR procedure. For all analyses, $P \leq 0.05$ was considered significant and $P>0.05$ but $\leq 0.10$ was considered a tendency.

\section{RESULTS}

\section{Intakes and Growth}

During the preweaning phase, heifers fed the low preweaning diet (LL and LH) had a relatively consistent milk intake before $8 \mathrm{wk}$ of age, averaging (mean \pm SEM) $4.9 \pm 0.1 \mathrm{~L} / \mathrm{d}$, with $90 \%$ of heifers consuming between 4.4 and $5.2 \mathrm{~L} / \mathrm{d}$. Overall milk intake before wk 8 was $8.3 \pm 0.1 \mathrm{~L} / \mathrm{d}$ in heifers fed the high preweaning diet (HH and HL), which was greater than that in heifers fed the low preweaning diet $(P<0.01)$. Milk intake of heifers fed the high preweaning diet was more variable in wk $1(6.1 \pm 0.3 \mathrm{~L} / \mathrm{d})$ and wk $2(8.0 \pm 0.4 \mathrm{~L} / \mathrm{d})$, but it was more consistent between wk 3 and 7 (9.0 \pm $0.1 \mathrm{~L} / \mathrm{d}$ ), with $95 \%$ of heifers consuming more than 7.8 $\mathrm{L} / \mathrm{d}$. Starter intake before wk 8 of age was greater in heifers fed the low preweaning diet than in heifers fed the high preweaning $\operatorname{diet}(P<0.01)$. Before wk 4 and from wk 5 to 8 , starter intake averaged (mean \pm SEM) $128.8 \pm 26.2$ and $762.5 \pm 67.3 \mathrm{~g} / \mathrm{d}$, respectively, for heifers fed the low preweaning diet and $47.6 \pm 10.8$ and $237.8 \pm 31.5 \mathrm{~g} / \mathrm{d}$, respectively, for heifers fed the high preweaning diet. Overall ME intake (mean \pm SEM) before wk 8 was $3.5 \pm 0.1 \mathrm{Mcal} / \mathrm{kg}$ for heifers fed the low preweaning diet and $4.9 \pm 0.1 \mathrm{Mcal} / \mathrm{kg}$ for heifers fed the high preweaning $\operatorname{diet}(P<0.01)$. At wk 8 of age, heifers fed low and high preweaning diets weighed $73.4 \pm 2.5$ and $82.1 \pm 2.5 \mathrm{~kg}$, respectively $(P=0.01)$. From wk 11 to 25 , ME intake was $13.2 \pm 3.3$ and 17.2 $\pm 4.2 \mathrm{Mcal} / \mathrm{kg}$ for heifers fed low and high postweaning diets, respectively $(P<0.01)$. Toward the end of the treatment period at wk 25, heifers fed low and high postweaning diets weighed (mean \pm SEM) $230.5 \pm 2.5$ and $247.0 \pm 2.5 \mathrm{~kg}$, respectively $(P<0.01)$.

Body weight averaged (LSM \pm SEM) $242.5 \pm 3.6$ $\mathrm{kg}$ at $26 \mathrm{wk}$ of age and increased $(P<0.001)$ to 286.3 $\pm 3.6 \mathrm{~kg}$ at wk 33. During the prepubertal phase, no significant effect of preweaning diet $(P=0.61)$ and no interaction between preweaning diet and postweaning $\operatorname{diet}(P=0.52)$ were observed on BW. However, heifers fed the high postweaning diet tended to have greater BW than those fed the low postweaning diet (269.9 \pm 5.3 vs. $257.7 \pm 4.0 \mathrm{~kg} ; P=0.08$; Figure 2a). Hip height was $122.6 \pm 0.6 \mathrm{~cm}$ at wk 26 and increased $(P<0.001)$ to $128.1 \pm 0.5 \mathrm{~cm}$ at wk 33. During the prepubertal phase, hip height was not affected by preweaning diet $(P=0.85)$, postweaning $\operatorname{diet}(P=0.35)$, or their interaction $(P=0.49$; Figure $2 \mathrm{~b})$.

\section{Reproductive Development in the Prepubertal Phase}

The endometrial thickness averaged $(\mathrm{LSM} \pm \mathrm{SEM})$ $10.7 \pm 0.4 \mathrm{~mm}$ at wk 26 of age and increased $(P<0.001)$ to $12.5 \pm 0.4 \mathrm{~mm}$ at wk 33. Endometrial thickness did not differ $(P=0.73)$ between heifers fed the low and high preweaning diets, but it was greater in heifers that received the high postweaning diet compared with the low postweaning diet $(12.0 \pm 0.4$ vs. $10.8 \pm 0.3 \mathrm{~mm}$; $P=0.01$; Figure 3a). No significant interactions were observed between dietary treatments or between treatments and week of age $(P>0.10)$. Similarly, the size of the largest follicle changed over time $(P=0.03)$ and tended to be larger in wk 32 than in wk $28(11.8 \pm 0.3$ vs. $10.8 \pm 0.3 \mathrm{~mm} ; P=0.08)$. Largest follicle size did not differ $(P=0.84)$ between heifers fed the low and high preweaning diets and was not affected $(P=0.12)$ by the interaction between preweaning diet and postweaning diet, but heifers offered the high postweaning diet had greater largest follicle size than those offered the low postweaning diet $(11.8 \pm 0.3$ vs. $10.9 \pm 0.2 ; P$ $=0.04$; Figure $3 \mathrm{~b}$ ).

The number of class 2 or 3 follicles did not change over time $(P>0.10)$. The number $(\mathrm{LSM} \pm \mathrm{SEM})$ of class 2 follicles was smaller in heifers fed a low preweaning diet than in those fed a high preweaning diet $(1.1 \pm 0.1$ vs. $1.6 \pm 0.1 ; P=0.02$; Figure $4 \mathrm{a})$, but it was not significantly influenced by postweaning diet 


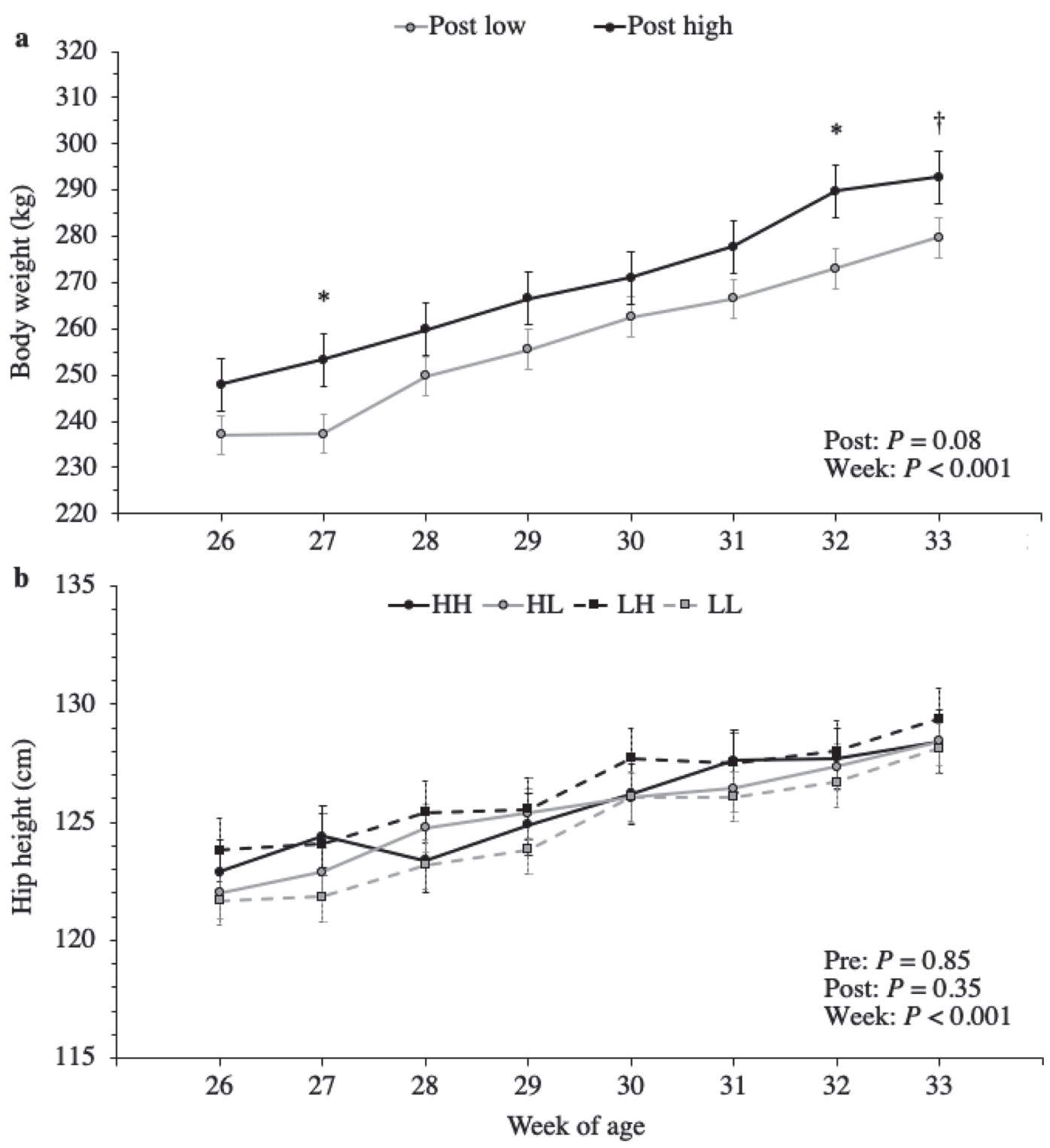

Figure 2. (a) Effects of postweaning (Post) dietary plane of nutrition (low $=70 \%$ of concentrate dry TMR, gray line; high $=85 \%$ of concentrate dry TMR, black line) before 26 wk of age on BW from 26 to 33 wk of age. (b) Effects of preweaning (Pre; low = 5 L of whole milk/d, dashed lines; high $=10 \mathrm{~L}$ of whole milk/d, solid lines) and postweaning dietary planes of nutrition before 26 wk of age on hip height from 26 to 33 wk of age in 28 prepubertal Holstein heifers. LL = low preweaning-low postweaning; HL = high preweaning-low postweaning; LH = low preweaning-high postweaning; $\mathrm{HH}=$ high preweaning-high postweaning. Body weight tended to differ between low and high postweaning planes of nutrition $(262.2 \pm 4.6$ vs. $265.4 \pm 4.6 \mathrm{~kg} ; P=0.08)$. In both panels, error bars represent SEM. For both variables, there was no significant interaction between pre- and postweaning diets. ${ }^{*}$ Body weight was affected by postweaning diet (high $>$ low; $P<0.03$ ) at individual time points. $\dagger$ Body weight tended to differ by postweaning weight (high $>$ low; $P=0.07$ ) at wk 33 .

$(P=0.48)$ or by the interaction between preweaning diet and postweaning diet $(P=0.10)$. The number of class 3 follicles did not differ between preweaning diet groups $(P=0.88)$ and was not affected by the interaction between preweaning diet and postweaning diet $(P=0.21)$. However, heifers fed the low postweaning diet had fewer class 3 follicles than heifers fed the high postweaning $\operatorname{diet}(1.0 \pm 0.1$ vs. $1.2 \pm 0.1 ; P=0.03$; Figure $4 b$ ).

\section{Characteristics of the Estrous Cycle in the Postpubertal Phase}

At d 1 of the estrous cycle, heifers averaged (mean \pm SD) $39 \pm 5$ wk of age, which was not different among treatment groups $(P>0.10)$. The overall (LSM \pm SEM) CL volume throughout the estrous cycle was $3,319.0 \pm 131.2 \mathrm{~mm}^{3}$, and no effects of preweaning diet $(P=0.33)$, postweaning diet $(P=0.91)$, or their inter- 

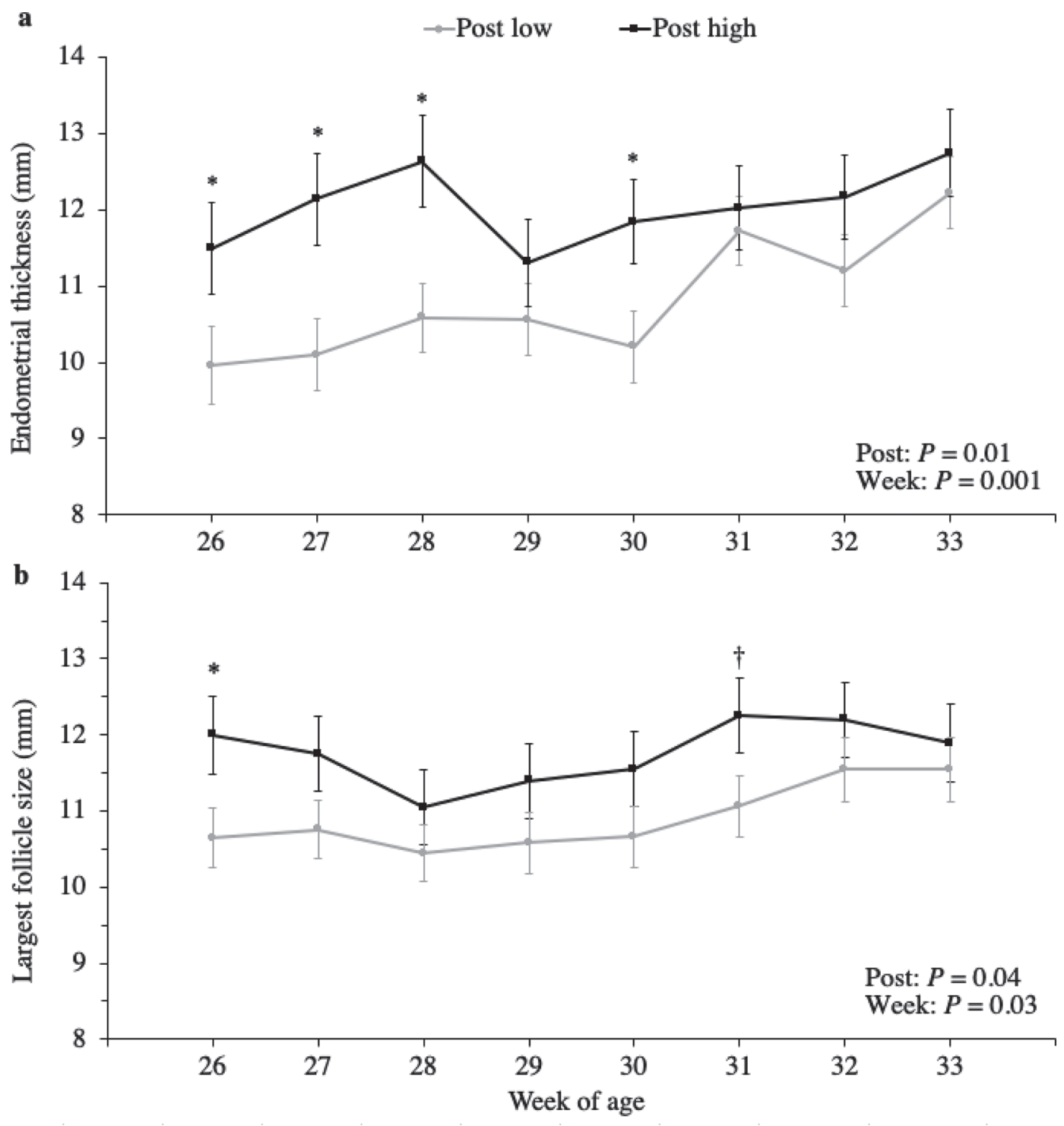

Figure 3. Effects of postweaning (Post) dietary plane of nutrition (low $=70 \%$ of concentrate dry TMR, gray line; high $=85 \%$ of concentrate dry TMR, black line) before $26 \mathrm{wk}$ of age on (a) endometrial thickness and (b) largest follicle size in 28 prepubertal Holstein heifers from 26 to 33 wk of age. Overall, both the endometrial thickness (low $=10.8 \pm 0.3 \mathrm{~mm}$; high $=12.0 \pm 0.4 \mathrm{~mm} ; P=0.01)$ and the largest follicle size (low $=10.9 \pm 0.2 \mathrm{~mm}$; high $=11.8 \pm 0.3 \mathrm{~mm} ; P=0.04)$ differed between postweaning dietary groups. In both panels, error bars represent SEM. For both variables, there were no differences between preweaning dietary groups or interactions between pre- and postweaning diets $(P>0.10)$. *Endometrial thickness and largest follicle size differed $(P \leq 0.05)$ between postweaning diets at individual time points. $\dagger$ Largest follicle size tended to differ $(P=0.06)$ between postweaning diets at wk 31 .

action $(P=0.43)$ were observed on CL volume (Figure 5a). Overall (LSM $\pm \mathrm{SEM}) \mathrm{P} 4$ concentration was 3.0 $\pm 0.2 \mathrm{ng} / \mathrm{mL}$, and no differences $(P>0.10)$ among dietary treatments (preweaning, postweaning) or their interaction were observed on P4 dynamics (Figure 5b). Similarly, dynamics of CL volume from $6 \mathrm{~d}$ before to $2 \mathrm{~d}$ after luteolysis did not differ $(P>0.10)$ between dietary treatments or by their interaction (Figure 6a). Overall $\mathrm{P} 4$ concentrations from $6 \mathrm{~d}$ before to $2 \mathrm{~d}$ after luteolysis were not affected by dietary treatments or their interaction $(P>0.10)$. However, there was a significant interaction between postweaning diet and day of the cycle $(P=0.01)$ : $\mathrm{P} 4$ concentration was lower in heifers fed a high postweaning diet than in those fed a low postweaning diet at $4 \mathrm{~d}$ preceding luteolysis $(6.1 \pm$ 0.4 vs. $7.7 \pm 0.4 \mathrm{ng} / \mathrm{mL} ; P<0.01$ ), whereas it tended to be greater in heifers fed a high postweaning diet than in those fed a low postweaning diet at the day of confirmed luteolysis $(1.7 \pm 0.4$ vs. $0.7 \pm 0.4 \mathrm{ng} / \mathrm{mL}$; $P=0.06$; Figure $6 \mathrm{~b}$ ). None of the other estrous cycle 

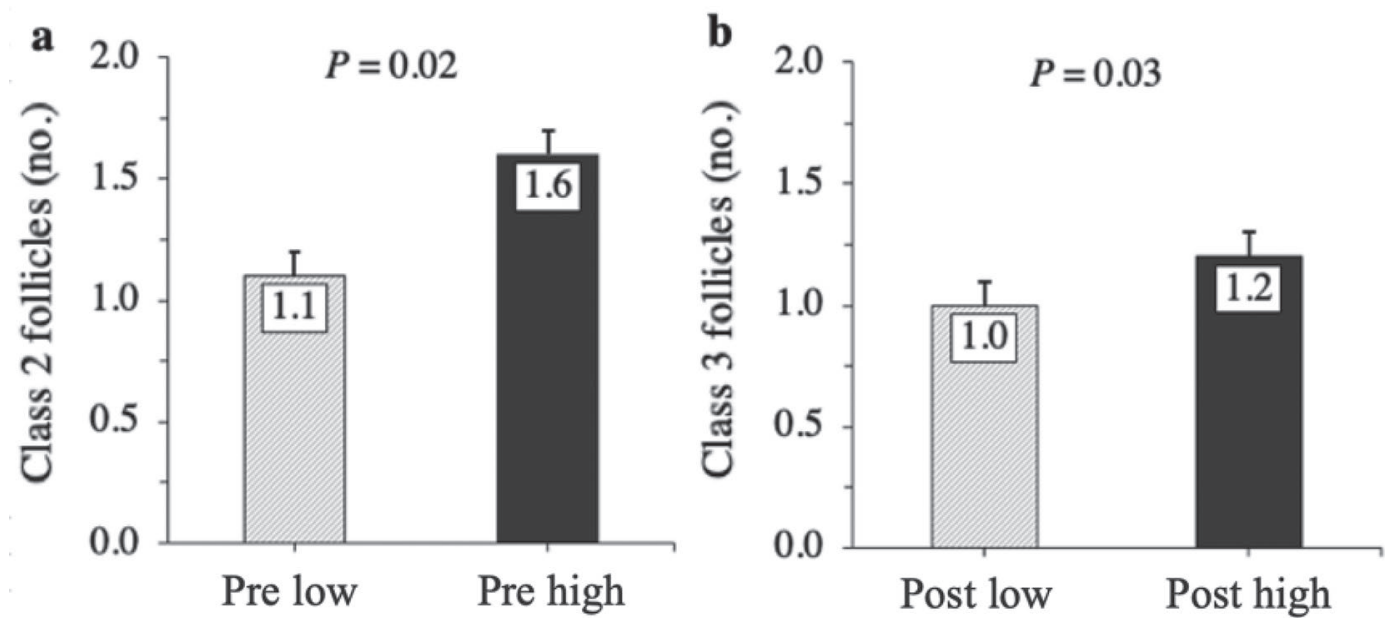

Figure 4. (a) Effects of preweaning (Pre) dietary plane of nutrition (low $=5 \mathrm{~L}$ of whole milk/d, gray bars; high $=10 \mathrm{~L}$ of whole milk/d, black bars) before 26 wk of age on the overall number of class $2(6-9 \mathrm{~mm})$ follicles between 26 and 33 wk of age in 28 prepubertal Holstein heifers. (b) Effects of postweaning (Post) dietary plane of nutrition (low $=70 \%$ of concentrate dry TMR, gray bars; high $=85 \%$ of concentrate dry TMR, black bars) before $26 \mathrm{wk}$ of age on the number of class 3 (>9 mm) follicles between 26 and 33 wk of age in 28 prepubertal Holstein heifers. In both panels, error bars represent SEM. For both variables, no effects of week of age and no significant interactions between pre- and postweaning diets were observed.

parameters measured ( $\mathrm{P} 4$ peak and slope, luteolysis slope, luteal phase length, cycle length, or preovulatory follicle size) were affected by pre- or postweaning dietary treatments or by their interaction (Table 2).

The number of antral follicles at $\mathrm{d} 1$ of the estrous cycle was not affected by preweaning $\operatorname{diet}(P=0.76)$ or by the interaction between preweaning diet and postweaning diet $(P=0.50)$. However, heifers fed the high postweaning diet had more antral follicles at $\mathrm{d} 1$ than did heifers fed the low postweaning diet (31.4 \pm 2.2 vs. $21.4 \pm 2.3 ; P<0.001$; Figure $7 \mathrm{a}$ ). The number of class 2 and 3 follicles $(\geq 6 \mathrm{~mm})$ at $\mathrm{d} 3$ of the estrous cycle was not influenced by preweaning $\operatorname{diet}(P=0.16)$ or by the interaction between preweaning diet and postweaning diet $(P=0.28)$. Nonetheless, heifers fed the high postweaning diet tended $(P=0.06)$ to have more class 2 and 3 follicles at $d 3$ than heifers fed the low postweaning diet (Figure 7b). Peak estrous activity was not influenced by dietary treatments or by their interaction $(P>0.10)$, but estrous activity was significantly increased in all heifers on $\mathrm{d}-2$ and -1 preceding ovulation (Figure 8). Pearson correlation coefficients among variables evaluated in the postpubertal phase are presented in Table 3.

\section{DISCUSSION}

The present work investigated carryover effects of differing planes of nutrition offered during the pre- and postweaning phases before $26 \mathrm{wk}$ of age on prepubertal reproductive tract development and postpubertal estrous cycle characteristics. In accordance with the findings of the present study, a previous work described greater ME intake, BW, and circulating IGF-1 during the preweaning phase in Holstein heifers offered 10 versus 5 L of whole milk/d (Haisan et al., 2018). During the postweaning phase, Groen et al. (2015) fed Holstein calves similar planes of nutrition (TMR with 85:15 vs. 70:30 concentrate:straw ratio) from wk 17 to 23 of age and reported increased DMI and ADG in calves offered the diet with greater concentrate level. An interesting finding from that work (Groen et al., 2015) was that calves fed more straw (70:30 vs. 85:15) had greater feed sorting and increased feeding time after feed delivery. Such behavior carried over after all calves were transitioned to a common diet, which could possibly have negative effects on future performance. In the present study, BW increased from wk 26 to 33 and tended to be greater in heifers offered the high postweaning diet than in those offered the low postweaning diet (Figure 2a). Regardless of diets, heifers in the present study were much heavier at wk 26 of age $(242.5 \mathrm{~kg})$ than those reported in previous studies evaluating Holstein heifers at a similar age [ 190 kg in Shamay et al. (2005); 200 $\mathrm{kg}$ in Davis Rincker et al. (2011)].

The development of the reproductive tract in heifers is expected to occur more rapidly in early stages of life (Atkins et al., 2013). The most rapid increase in uterine diameter (9 to $16 \mathrm{~mm}$ ) has been reported to occur from 2 to $10 \mathrm{wk}$ of age, followed by no significant increase until wk 32, whereas the increase in largest follicle size occurred from 8 to 14 wk of age ( 6 to $8 \mathrm{~mm})$ and remained unchanged until wk 38 (Honaramooz et al., 2004). An early study revealed that uterine size in- 
creased at a similar rate as body growth until 25 wk of age, whereas the number of follicles increased until wk 17 (Desjardins and Hafs, 1969). In the present study, although endometrial thickness was greater from 26 to 33 wk of age in heifers that received the high postweaning diet than in those that received the low postweaning diet, it did not differ between the preweaning diet groups. Using a different approach to compare dietary planes of nutrition, Wilson et al. (2017) compared calves that were fed restricted versus enhanced milk replacer diets and observed reduced number and size of uterine glands at $8 \mathrm{wk}$ of age in calves receiving the restricted milk replacer diet. Interestingly, however, they reported that the negative effect of restricted versus enhanced milk replacer diet observed on uterine glandular development at 8 wk of age was no longer evident 2 wk after weaning (Wilson et al., 2017). Notably, in the present study, the increase in endometrial thickness from 26 to $33 \mathrm{wk}$ was not consistent among weeks in the high postweaning diet group (Figure 3a). As uterine glands are expected to become progressively larger after $26 \mathrm{wk}$ of age (Desjardins and Hafs, 1969), the greater endometrial thickness observed before wk 29 in heifers offered the high compared with low postweaning diet (Figure 3a) indicates that uterine development occurred earlier in those heifers that received the increased plane of nutrition with greater protein and energy contents. The literature reporting endometrial thickness in prepuber-

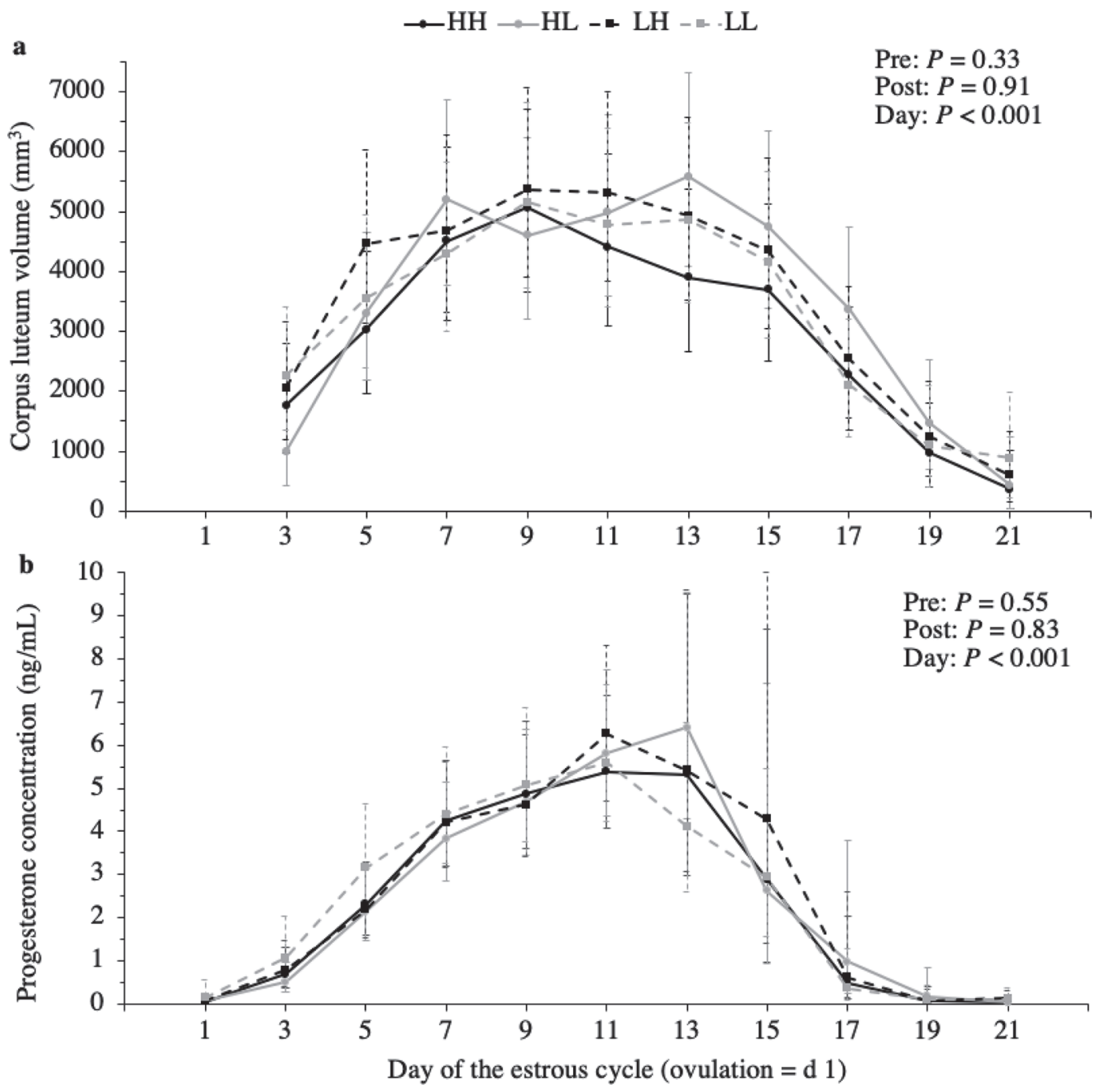

Figure 5. Profiles of (a) corpus luteum volume and (b) progesterone concentrations throughout the estrous cycle in 28 postpubertal Holstein heifers that received different preweaning (Pre; low $=5 \mathrm{~L}$ of whole milk/d, dashed lines; high $=10 \mathrm{~L}$ of whole milk/d, solid lines) and postweaning (Post; low $=70 \%$ of concentrate dry TMR, gray lines; high $=85 \%$ of concentrate dry TMR, black lines) dietary planes of nutrition before 26 wk of age. $\mathrm{LL}=$ low preweaning-low postweaning; $\mathrm{HL}=$ high preweaning-low postweaning; $\mathrm{LH}=$ low preweaning-high postweaning; $\mathrm{HH}=$ high preweaning-high postweaning. In both panels, error bars represent the 95\% CI of the back-transformed adjusted LSM. For both variables, no significant interactions between pre- and postweaning diets were observed. 
$\mathbf{a}$

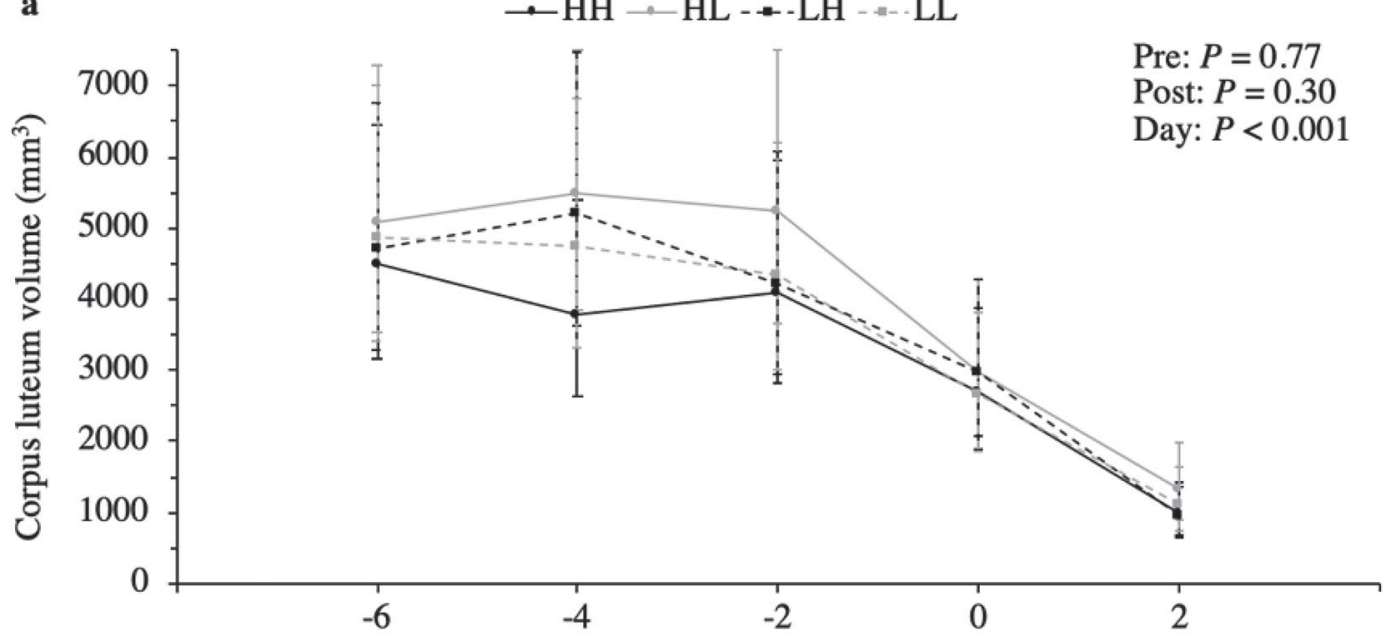

.

b

10
9
8
7
6
5
4
3
2
1
0

.

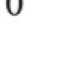


licular growth can be hypothesized. For instance, Fiol et al. (2017) compared prepubertal Holstein heifers according to their social behavior and reported that relative to subordinate heifers, dominant heifers achieved a greater BW, had greater circulating glucose, greater number of follicles, greater maximum follicle diameter, and achieved puberty earlier, likely because they had more frequent access to feed due to their dominant demeanor. Furthermore, decreased circulating insulin and IGF-1, induced by reducing the dietary energy contents in the postweaning diet (Armstrong et al., 2001) or by feed restriction (Lents et al., 2013), were negatively associated with the dominant follicle size in cycling heifers (Armstrong et al., 2001; Lents et al., 2013). Our findings suggest that the effects of increasing dietary energy and protein contents from 10 to 25 wk of age on ME intake and circulating IGF-1 (Rosadiuk, 2018) carried over to beyond 26 wk of age and resulted in an increased number of follicles and greater size of the largest follicle in the prepubertal phase.

The mean $( \pm$ SEM) age at puberty and BW of the heifers evaluated in the present study were reported by Rosadiuk (2018) as $35.8 \pm 0.3 \mathrm{wk}$ and $318.2 \pm 8.5 \mathrm{~kg}$, respectively. Contrary to previous studies that reported earlier puberty in heifers offered elevated planes of nutrition during the preweaning phase (Shamay et al.,
2005; Davis Rincker et al., 2011) or the postweaning phase (Chelikani et al., 2003), no effects of preweaning diet or postweaning diet on age or BW at puberty were observed by Rosadiuk (2018). This possibly occurred because the low postweaning diet offered also had a relatively high energy content (Table 1), explaining why regardless of planes of nutrition, age at puberty reported by Rosadiuk (2018) was considerably lower compared with that reported by others, often varying from 38 to more than 70 wk of age (Chelikani et al., 2003; Shamay et al., 2005; Davis Rincker et al., 2011).

It is important to note that 8 out of the 18 heifers that received the high postweaning plane of nutrition were excluded from the evaluation of the prepubertal phase parameters because they attained puberty unexpectedly early compared with previous studies. If the early attainment of puberty in those 8 heifers was at least a partial manifestation of positive effects of the increased postweaning nutritional plane on reproductive development, the deliberate exclusion of those 8 heifers could have biased the final data set used for evaluation of prepubertal reproductive development. In this scenario, the high postweaning diet group in the final data set could be overrepresented by heifers that, for some unknown reason, did not respond well to the increased postweaning nutritional plane. The introduction of

Table 2. Effects of preweaning (low vs. high) and postweaning (low vs. high) planes of nutrition before 26 wk of age on estrous cycle characteristics in 28 postpubertal Holstein heifers

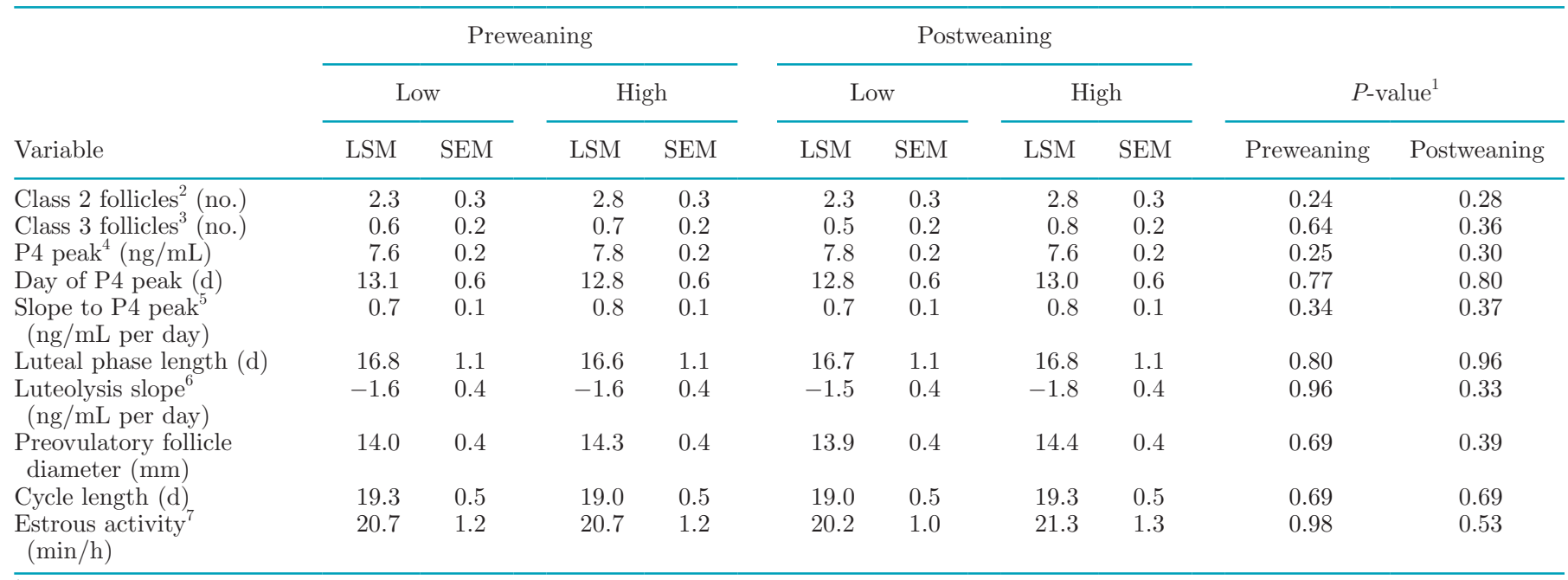

\footnotetext{
${ }^{1}$ No interaction between preweaning diet and postweaning diet was observed for the presented variables.

${ }^{2}$ Number of follicles between 6 and $9 \mathrm{~mm}$ at d 3 (d $1=$ day of confirmed ovulation).

${ }^{3}$ Number of follicles $>9 \mathrm{~mm}$ at $\mathrm{d} 3$.

${ }^{4}$ Progesterone $(\mathrm{P} 4)$ concentration at the first increase in $\mathrm{P} 4$ to above the average of the 2 greatest $\mathrm{P} 4$ concentrations recorded during the estrous cycle.

${ }^{5}$ Average daily change in $\mathrm{P} 4$ concentrations between day of confirmed ovulation and day of $\mathrm{P} 4$ peak.

${ }^{6}$ Average daily change in $\mathrm{P} 4$ concentrations between day before confirmed luteolysis and day on which $\mathrm{P} 4$ concentration subsequently declined to $<25 \%$ of the $\mathrm{P} 4$ peak.

${ }^{7}$ Average minutes per hour of high activity on the day of estrus evaluated in 21 heifers. Estrus = day with the highest activity values recorded by an ear tag-based activity monitoring system (CowManager, Harmelen, the Netherlands) between luteolysis and subsequent confirmed ovulation.
} 

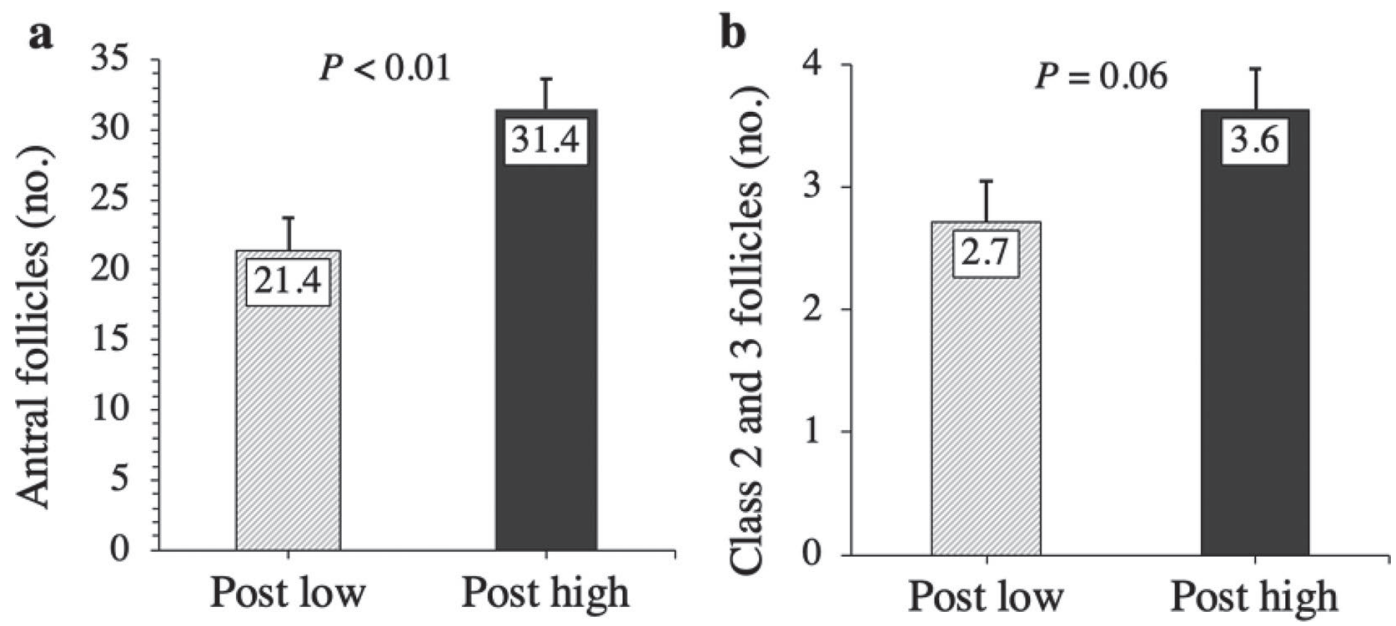

Figure 7. Effects of postweaning (Post) dietary plane of nutrition (low $=70 \%$ of concentrate dry TMR, gray bars; high $=85 \%$ of concentrate dry TMR, black bars) before 26 wk of age on (a) the number of antral follicles at d 1 (day of confirmed ovulation) of the estrous cycle and (b) the number of class 2 and $3(\geq 6 \mathrm{~mm})$ follicles at d 3 of the estrous cycle in 28 postpubertal Holstein heifers. In both panels, error bars represent SEM. For both variables, no effects of preweaning dietary plane of nutrition and no interactions between pre- and postweaning diets were observed.

such bias to the final data set could have reduced the chances of detecting any positive treatment effects in case they truly existed. Therefore, future studies aiming to investigate the effects of planes of nutrition on reproductive development in Holstein heifers managed similarly to those in the present study should consider monitoring ovarian activity and reproductive tract development from an earlier age.
During the estrous cycle evaluated in the postpubertal phase, neither the preweaning diet nor the postweaning diet influenced luteal function, such as dynamics of CL volume and P4 concentrations (Figure 5), P4 peak, slope to $\mathrm{P} 4$ peak, luteolysis slope, and luteal phase length (Table 2). Similarly, no immediate effects of increasing the dietary energy and protein contents were observed by Chelikani et al. (2003) on

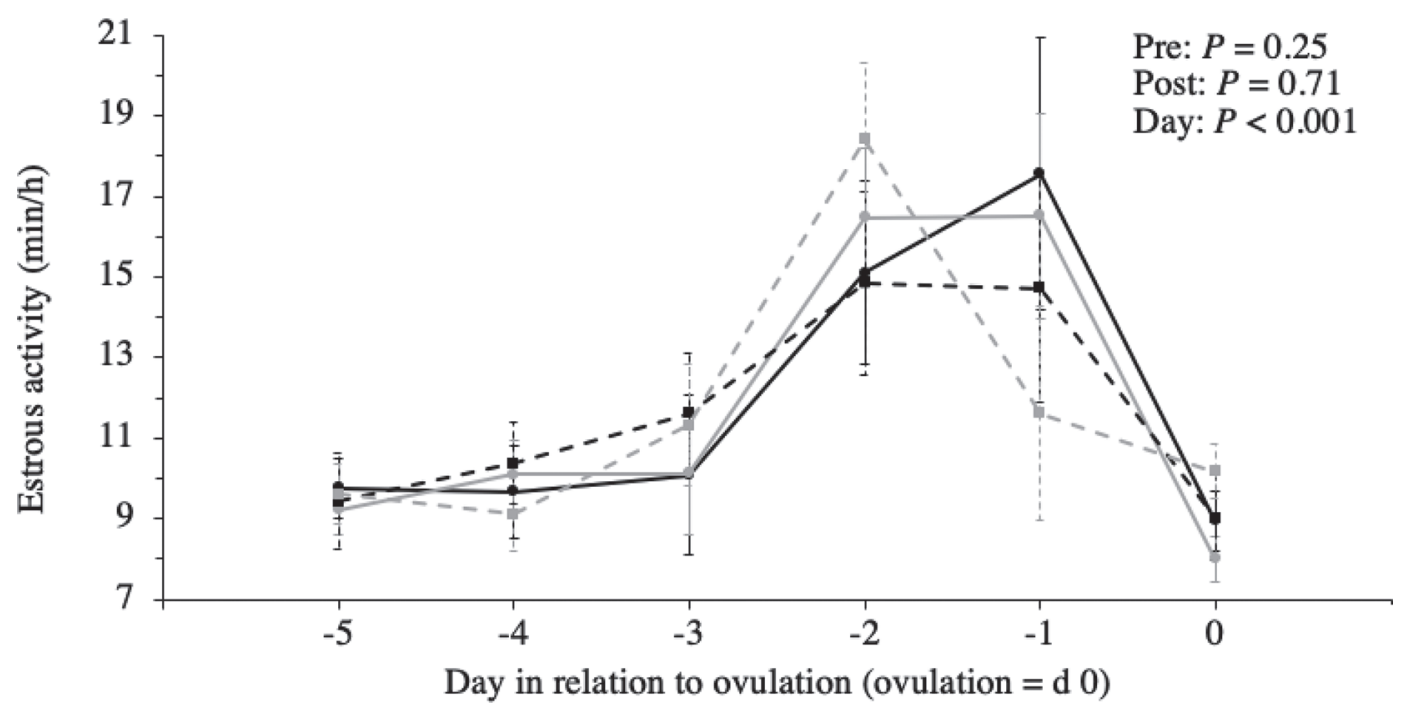

Figure 8. Changes in estrous activity (defined as the average min/h of high activity as determined by an ear tag-based activity monitoring system; CowManager, Harmelen, the Netherlands) in relation to day of confirmed ovulation (d 0) at the end of the estrous cycle evaluated in 21 Holstein heifers that received different preweaning (Pre; low $=5 \mathrm{~L}$ of whole milk/d, dashed lines; high $=10 \mathrm{~L}$ of whole milk $/ \mathrm{d}$, solid lines) and postweaning (Post; low $=70 \%$ of concentrate dry TMR, gray lines; high $=85 \%$ of concentrate dry TMR, black lines) dietary planes of nutrition before 26 wk of age. LL = low preweaning-low postweaning; HL = high preweaning-low postweaning; LH = low preweaning-high postweaning; $\mathrm{HH}=$ high preweaning-high postweaning. Error bars represent SEM. No significant interaction between pre- and postweaning diets was observed. 


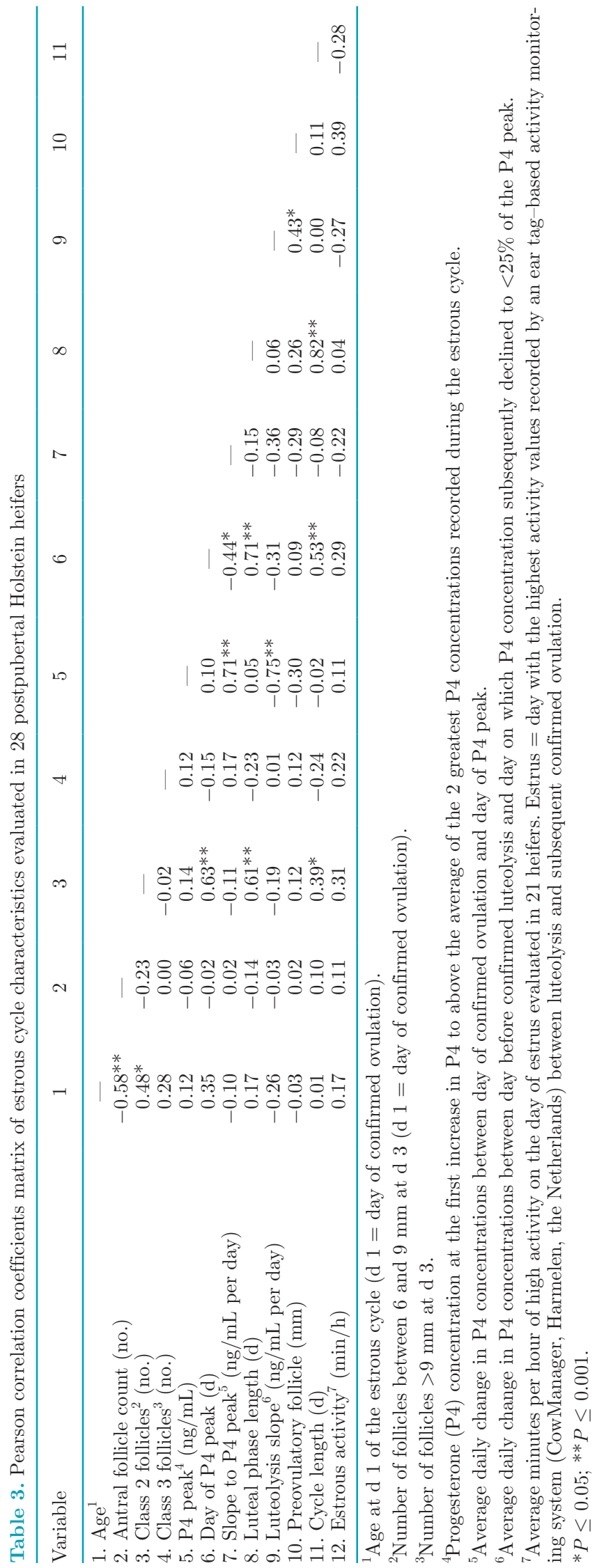

CL or P4 dynamics in the second postpubertal estrous cycle. Conversely, Armstrong et al. (2001) compared high- and low-energy diets offered during the estrous cycle and observed higher P4 concentrations during the luteal phase in heifers fed the high-energy diet; these findings were supported by Gutiérrez et al. (1997). However, we did not see a carryover effect of increasing dietary energy and protein contents before 26 wk of age on postpubertal P4 concentrations. However, reduced $\mathrm{P} 4$ concentration $4 \mathrm{~d}$ preceding luteolysis and elevated $\mathrm{P} 4$ at the day of confirmed luteolysis observed in heifers offered the high postweaning diet compared with those offered the low postweaning diet (Figure 6b) could have occurred, at least partially, if heifers had an incomplete luteolysis that initiated around $\mathrm{d}-4$ but was not completed until d 0 . Such differences at individual time points related to luteolysis should be interpreted with caution because, in the present study, luteolysis was defined based on the decline in $\mathrm{P} 4$ concentrations in 3 consecutive samples obtained at 2 d-intervals, so the exact day of luteolysis likely varied. To precisely investigate variations in luteal dynamics related to the luteolysis process, more frequent P4 measurements and US examinations should be performed.

An interesting finding was the carryover effect of postweaning diet on the total number of antral follicles evaluated at $\mathrm{d} 1$ of the estrous cycle (Figure 7). Investigation of antral follicle count in cattle has been gaining popularity due to its positive associations with in vivo (Cushman et al., 2009; Mossa et al., 2012) and in vitro (Taneja et al., 2000; Ireland et al., 2007) fertility. For instance, dairy cows with high $(\geq 25)$ antral follicle count had greater pregnancy risk than those with low ( $\leq 15)$ antral follicle count (Mossa et al., 2012), and oocyte recovery and pregnancy risk of in vitroproduced embryos were positively correlated with the antral follicle count before gonadotropin stimulation in 8- to 13-wk-old Holstein calves (Taneja et al., 2000). Furthermore, beef heifers with a high $(\geq 25)$ versus low $(\leq 15)$ antral follicle count had more healthy oocytes (Ireland et al., 2008), yielded more oocytes (from unstimulated ovaries), and yielded more total and transferable embryos (after superovulation), and more in vitro-fertilized oocytes became blastocysts and hatched blastocysts (Ireland et al., 2007). Therefore, antral follicle count is a trait with potential to be incorporated into reproductive tract scoring systems and selection criteria (Atkins et al., 2013) and may be useful for improving performance of heifers subjected to embryo transfer programs (Ireland et al., 2007).

Factors that influence antral follicle count are not established; however, a previous report showed that beef heifers with a high $(\geq 25)$ antral follicle count had greater birth $\mathrm{BW}$ and improved subsequent fertility 
compared with heifers with a lower $(\leq 15)$ antral follicle count (Cushman et al., 2009). Antral follicle count was negatively associated with age (Table 3), which possibly occurred because heifers enrolled in the study at a younger age were those that achieved puberty earlier, indicating advanced reproductive development in such heifers. The present study indicates that an elevated postweaning plane of nutrition before $26 \mathrm{wk}$ of age positively influenced the number of antral follicles during the postpubertal estrous cycles, which is relevant particularly because antral follicle counts are highly repeatable within heifers (Burns et al., 2005). Similarly, 2- to 3-yr-old cycling heifers fed twice the maintenance requirement until d 3 of the estrous cycle had an increased number of small follicles at $\mathrm{d} 1$ and 2 of the estrous cycle compared with heifers fed either the maintenance requirement or less (Gutiérrez et al., 1997). In addition to the dietary effect on antral follicle count observed in the present study, diet also seemed to influence follicular growth as the number of class 2 and 3 follicles tended to differ among plane of nutrition groups. By comparing effects of a high versus low plane of nutrition in the postpubertal phase, feeding the high-plane diet was associated with increased dominant follicle size (Armstrong et al., 2001; Chelikani et al., 2003) but not with FSH concentrations (Gutiérrez et al., 1997), number of small $(<8 \mathrm{~mm})$ follicles (Gutiérrez et al., 1997; Armstrong et al., 2001), or follicular growth (Chelikani et al., 2003). Finally, the present study suggests no carryover effects of increasing the pre- or postweaning plane of nutrition on the intensity of estrous activity (Figure 8).

Increasing the preweaning plane of nutrition through feeding 10 versus $5 \mathrm{~L}$ of milk/d increased the number of class $2(6-9 \mathrm{~mm})$ follicles in the prepubertal phase but did not influence postpubertal estrous cycle characteristics. Offering a postweaning plane of nutrition with increased starter:straw ratio (85:15 vs. $70: 30)$ and elevated energy (2.9 vs. $2.5 \mathrm{Mcal} / \mathrm{kg}$ ) and protein $(25.0$ vs. $21.1 \% \mathrm{CP}$ ) contents until 25 wk of age positively affected endometrial thickness, follicular size, and number of follicles in the prepubertal phase and antral follicle count in the postpubertal phase. Potential implications of the increased follicular population observed in heifers that received the elevated postweaning plane of nutrition include improved reproductive performance and fertility and better outcomes in embryo transfer programs.

\section{ACKNOWLEDGMENTS}

This research was supported by Alberta Livestock and Meat Agency and Alberta Milk (Edmonton, AB, Canada). The authors thank Trouw Animal Nutrition
(Guelph, ON, Canada) for donating the feed and Darrell Bignell of Alberta Agriculture and Forestry (Edmonton, AB, Canada) for providing technical assistance during the study. M. A. Steele's position was supported by Alberta Milk (Edmonton, AB, Canada), BC Dairy Association (Burnaby, BC, Canada), Dairy Farmers of Manitoba (Winnipeg, MB, Canada), Lallemand Animal Nutrition (Montreal, QC, Canada), Trouw Animal Nutrition (Guelph, ON, Canada), SaskMilk (Regina, SK, Canada), Westgen (Abbotsford, BC, Canada), and National Science and Engineering Research Council (Ottawa, ON, Canada).

\section{REFERENCES}

Armstrong, D. G., T. G. McEvoy, G. Baxter, J. J. Robinson, C. O. Hogg, K. J. Woad, R. Webb, and K. D. Sinclair. 2001. Effect of dietary energy and protein on bovine follicular dynamics and embryo production in vitro: Associations with the ovarian insulinlike growth factor system. Biol. Reprod. 64:1624-1632. https://doi .org/10.1095/biolreprod64.6.1624.

Atkins, J. A., K. G. Pohler, and M. F. Smith. 2013. Physiology and endocrinology of puberty in heifers. Vet. Clin. North Am. Food Anim. Pract. 29:479-492. https://doi.org/10.1016/j.cvfa.2013.07 .008 .

Brown, E. G., M. J. Vandehaar, K. M. Daniels, J. S. Liesman, L. T. Chapin, D. H. Keisler, and M. S. W. Nielsen. 2005. Effect of increasing energy and protein intake on body growth and carcass composition of heifer calves. J. Dairy Sci. 88:585-594. https://doi .org/10.3168/jds.S0022-0302(05)72722-3.

Burns, D. S., F. Jimenez-Krassel, J. L. Ireland, P. G. Knight, and J. J. Ireland. 2005. Numbers of antral follicles during follicular waves in cattle: Evidence for high variation among animals, very high repeatability in individuals, and an inverse association with serum follicle-stimulating hormone concentrations. Biol. Reprod. 73:54-62. https://doi.org/10.1095/biolreprod.104.036277.

Chelikani, P. K., J. D. Ambrose, and J. J. Kennelly. 2003. Effect of dietary energy and protein density on body composition, attainment of puberty, and ovarian follicular dynamics in dairy heifers. Theriogenology 60:707-725. https://doi.org/10.1016/S0093 $-691 \mathrm{X}(03) 00088-8$.

Cushman, R. A., M. F. Allan, L. A. Kuehn, W. M. Snelling, A. S. Cupp, and H. C. Freetly. 2009. Evaluation of antral follicle count and ovarian morphology in crossbred beef cows: Investigation of influence of stage of the estrous cycle, age, and birth weight. J. Anim. Sci. 87:1971-1980. https://doi.org/10.2527/jas.2008-1728.

Davis Rincker, L. E., M. J. VandeHaar, C. A. Wolf, J. S. Liesman, L. T. Chapin, and M. S. Weber Nielsen. 2011. Effect of intensified feeding of heifer calves on growth, pubertal age, calving age, milk yield, and economics. J. Dairy Sci. 94:3554-3567. https://doi.org/ 10.3168/jds.2010-3923.

Desjardins, C., and H. D. Hafs. 1969. Maturation of bovine female genitalia from birth through puberty. J. Anim. Sci. 28:502-507. https://doi.org/10.2527/jas1969.284502x.

Fiol, C., M. Carriquiry, and R. Ungerfeld. 2017. Social dominance in prepubertal dairy heifers allocated in continuous competitive dyads: Effects on body growth, metabolic status, and reproductive development. J. Dairy Sci. 100:2351-2359. https://doi.org/10 $.3168 /$ jds.2016-11840.

Geiger, A. J., C. L. M. Parsons, and R. M. Akers. 2016. Feeding a higher plane of nutrition and providing exogenous estrogen increases mammary gland development in Holstein heifer calves. J. Dairy Sci. 99:7642-7653. https://doi.org/10.3168/jds.2016-11283.

Gobikrushanth, M., P. A. Dutra, T. C. Bruinjé, M. G. Colazo, S. T. Butler, and D. J. Ambrose. 2017. Characterization of the variability and repeatability of gonadotropin-releasing hormone-induced luteinizing hormone responses in dairy cows within a synchronized 
ovulation protocol. J. Dairy Sci. 100:6753-6762. https://doi.org/ $10.3168 /$ jds.2016-12529.

Godden, S. M., J. P. Fetrow, J. M. Feirtag, L. R. Green, and S. J. Wells. 2005. Economic analysis of feeding pasteurized nonsaleable milk versus conventional milk replacer to dairy calves. J. Am. Vet. Med. Assoc. 226:1547-1554. https://doi.org/10.2460/javma.2005 .226 .1547 .

Groen, M. J., M. A. Steele, and T. J. DeVries. 2015. Short communication: Effect of straw inclusion rate in a dry total mixed ration on the behavior of weaned dairy calves. J. Dairy Sci. 98:2693-2700. https://doi.org/10.3168/jds.2014-8978.

Gutiérrez, C. G., J. Oldham, T. A. Bramley, J. G. Gong, B. K. Campbell, and R. Webb. 1997. The recruitment of ovarian follicles is enhanced by increased dietary intake in heifers. J. Anim. Sci. 75:1876-1884. https://doi.org/10.2527/1997.7571876x.

Haisan, J., M. Oba, D. J. Ambrose, and M. A. Steele. 2018. Short communication: The effects of offering a high or low plane of milk preweaning on insulin-like growth factor and insulin-like growth factor binding proteins in dairy heifer calves. J. Dairy Sci. 101:11441-11446. https://doi.org/10.3168/jds.2017-14339.

Honaramooz, A., J. Aravindakshan, R. K. Chandolia, A. P. Beard, P. M. Bartlewski, R. A. Pierson, and N. C. Rawlings. 2004. Ultrasonographic evaluation of the pre-pubertal development of the reproductive tract in beef heifers. Anim. Reprod. Sci. 80:15-29. https://doi.org/10.1016/S0378-4320(03)00136-2.

Ireland, J. L., D. Scheetz, F. Jimenez-Krassel, A. P. Themmen, F. Ward, P. Lonergan, G. W. Smith, G. I. Perez, A. C. Evans, and J. J. Ireland. 2008. Antral follicle count reliably predicts number of morphologically healthy oocytes and follicles in ovaries of young adult cattle. Biol. Reprod. 79:1219-1225. https://doi.org/10.1095/ biolreprod.108.071670.

Ireland, J. J., F. Ward, F. Jimenez-Krassel, J. L. Ireland, G. W. Smith, P. Lonergan, and A. C. O. Evans. 2007. Follicle numbers are highly repeatable within individual animals but are inversely correlated with FSH concentrations and the proportion of goodquality embryos after ovarian stimulation in cattle. Hum. Reprod. 22:1687-1695. https://doi.org/10.1093/humrep/dem071.

Khan, M. A., D. M. Weary, and M. A. G. von Keyserlingk. 2011 Invited review: Effects of milk ration on solid feed intake, weaning, and performance in dairy heifers. J. Dairy Sci. 94:1071-1081. https://doi.org/10.3168/jds.2010-3733.

Lents, C. A., F. J. White, N. H. Ciccioli, L. N. Floyd-White, I. Rubio, D. H. Keisler, L. J. Spicer, and R. P. Wettemann. 2013. Metabolic status, gonadotropin secretion, and ovarian function during acute nutrient restriction of beef heifers. J. Anim. Sci. 91:4146-4157. https://doi.org/10.2527/jas.2013-6342.

Monteiro, F. M., M. E. Z. Mercadante, C. M. Barros, R. A. Satrapa, J. A. V. Silva, L. Z. Oliveira, N. Z. Saraiva, C. S. Oliveira, and J. M. Garcia. 2013. Reproductive tract development and puberty in two lines of Nellore heifers selected for postweaning weight. Theriogenology 80:10-17. https://doi.org/10.1016/j.theriogenology.2013 .02 .013 .
Mossa, F., S. W. Walsh, S. T. Butler, D. P. Berry, F. Carter, P. Lonergan, G. W. Smith, J. J. Ireland, and A. C. O. Evans. 2012. Low numbers of ovarian follicles $\geq 3 \mathrm{~mm}$ in diameter are associated with low fertility in dairy cows. J. Dairy Sci. 95:2355-2361. https://doi .org/10.3168/jds.2011-4325.

Nepomuceno, D. D., A. V. Pires, M. V. C. Ferraz Jr., M. V. Biehl, J. R. S. Gonçalves, E. M. Moreira, and M. L. Day. 2017. Effect of pre-partum dam supplementation, creep-feeding and post-weaning feedlot on age at puberty in Nellore heifers. Livest. Sci. 195:58-62. https://doi.org/10.1016/j.livsci.2016.11.008

Radcliff, R. P., M. J. Vandehaar, L. T. Chapin, T. E. Pilbeam, D. K. Beede, E. P. Stanisiewski, and H. A. Tucker. 2000. Effects of diet and injection of bovine somatotropin on prepubertal growth and first-lactation milk yields of Holstein cows. J. Dairy Sci. 83:23-29. https://doi.org/10.3168/jds.S0022-0302(00)74850-8.

Rodríguez-Sánchez, J. A., A. Sanz, C. Tamanini, and I. Casasús. 2015. Metabolic, endocrine, and reproductive responses of beef heifers submitted to different growth strategies during the lactation and rearing periods. J. Anim. Sci. 93:3871-3885. https://doi.org/10 .2527/jas.2015-8994

Rosadiuk, J. P. 2018. The effects of differing planes of pre- and postweaning phase nutrition on intake, growth, select metabolite and hormone concentrations, and sexual development in Holstein heifer calves. MS Thesis. University of Alberta, Edmonton, AB, Canada. https://era.library.ualberta.ca/items/cf4f1be3-63d3-42d7-8b0e -b851389efb2a/download/5e505dfb-b5b3-4fef-9bec-f364874298a2.

Sartori, R., J. M. Haughian, R. D. Shaver, G. J. M. Rosa, and M. C. Wiltbank. 2004. Comparison of ovarian function and circulating steroids in estrous cycles of Holstein heifers and lactating cows. J. Dairy Sci. 87:905-920. https://doi.org/10.3168/jds.S0022 -0302(04)73235-X.

Shamay, A., D. Werner, U. Moallem, H. Barash, and I. Bruckental. 2005. Effect of nursing management and skeletal size at weaning on puberty, skeletal growth rate, and milk production during first lactation of dairy heifers. J. Dairy Sci. 88:1460-1469. https://doi org/10.3168/jds.S0022-0302(05)72814-9.

Soberon, F., and M. E. Van Amburgh. 2013. Lactation biology symposium: The effect of nutrient intake from milk or milk replacer of preweaned dairy calves on lactation milk yield as adults: A meta-analysis of current data. J. Anim. Sci. 91:706-712. https:// doi.org/10.2527/jas.2012-5834.

Taneja, M., P. E. Bols, A. Van de Velde, J. C. Ju, D. Schreiber, M. W. Tripp, H. Levine, Y. Echelard, J. Riesen, and X. Yang. 2000. Developmental competence of juvenile calf oocytes in vitro and in vivo: Influence of donor animal variation and repeated gonadotropin stimulation. Biol. Reprod. 62:206-213. https://doi.org/10 .1095/biolreprod62.1.206.

Wilson, M. L., S. R. McCoski, A. J. Geiger, R. M. Akers, S. E. Johnson, and A. D. Ealy. 2017. The influence of postnatal nutrition on reproductive tract and endometrial gland development in dairy calves. J. Dairy Sci. 100:3243-3256. https://doi.org/10.3168/jds .2016-11880. 